\title{
Avaliação das propriedades físicas, químicas e mecânicas de filmes de amido/PVA/argila bentonita modificados com metacrilato de glicidila
}

\author{
Evaluation of the physical, chemical and \\ mechanical properties of starch/PVA/bentonite clay \\ films modified with glycidyl methacrylate
}

\author{
Alberto Gonçalves Vieira de Carvalho Neto ${ }^{1}$ Dayse Iara dos Santos ${ }^{1}$, \\ Sandra Regina Rissato ${ }^{1}$, Margarida Juri Saeki ${ }^{3}$, Silvia Luciana Favaro ${ }^{2}$, \\ Eduardo Radovanovic ${ }^{2}$ Diogo Silva Pellosi ${ }^{4}$
}

\begin{abstract}
${ }^{1}$ Laboratório de Materiais Supercondutores e Nanoestruturados - LMSCN, Programa de Pós Graduação em Ciência e Tecnologia de Materiais, Universidade Estadual Paulista, CEP: 17033-360, Bauru, SP, Brasil.

${ }^{2}$ Laboratório de Química de Materiais e Sensores - LMSEM, Universidade Estadual de Maringá, CEP: 87020-900, Maringá, PR, Brasil.

${ }^{3}$ Instituto de Biociências de Botucatu, Universidade Estadual Paulista, CEP: 18618-689, Botucatu, SP, Brasil.

${ }^{4}$ Laboratório de Materiais Híbridos (LMH), Universidade Federal de São Paulo (UNIFESP), Rua São Nicolau, 210, Centro. CEP: 09913-030, Diadema, SP, Brasil

e-mail: mailto:alb_vieira@yahoo.com.br, dayse@fc.unesp.br, Sandra.rissato@unesp.br, slfavaro@hotmail.com, eradovanovic@uem.br,mjsaeki@ibb.unesp.br, diogo.pellosi@unifesp.br
\end{abstract}

\section{RESUMO}

Filmes constituídos por amido de mandioca, álcool polivinílico (PVA) e argila Bentonita (BNT) e glicerol como plastificante foram obtidos utilizando o método casting. A fim de aumentar a compatibilidade dos polímeros ao mineral e sua hidrofobicidade, estes foram posteriormente modificados quimicamente utilizando metacrilato de glicidila (GMA) para a substituição dos grupamentos hidroxilas por vinílicos. Este procedimento gerou filmes com excelente estabilidade a sorção de água e permeabilidade ao vapor de água $15 \%$ menor quando comparados coms os filmes sem modificação química. Adicionalmente, esta estratégia também resultou na melhora de $25 \%$ na resistência a tração, mantendo o mesmo módulo de Young mas, com tma leve diminuição na estabilidade térmica (início de degradação $14^{\circ} \mathrm{C}$ menor).

A adição da argila BNT gera filmes compósitos com propriedades, mecânicas, térmicas e físicas diferenciadas, contudo há uma dependência entre a quantidade de reforço e a distribuição estrutural das lamelas de argila na matriz. As modificações químicas foram comprovadas por RMN H ${ }^{1}$, FTIR, DRX e os filmes foram caracterizados por DRX, sorção e permeabilidade a água, ensaios mecânicos (tração, alongamento e módulo de Young) e TGA. A utilização de $1 \% \mathrm{~m} / \mathrm{m}$ deste reforço gera compósitos com BNT estruturalmente esfoliado, independentemente da prévia modificação com metacrilato de glicidila. Já a formulação com $5 \% \mathrm{~m} / \mathrm{m}$ gerou filmes compósitos intercalados. Qualquer outro teor de reforço exibe estruturas lamelares aglomeradas (empacotadas). Destaca-se que nas formulações reforçadas com 1\% de argila, houve melhora em cerca 30\% na resistência a tração com permeabilidade a água $60 \%$ menor, para cargas maiores de argila. Estes fatos apontam que as modificações propostas neste trabalho geraram propriedades promissoras para a produção de materiais de embalagem biodegradáveis.

Palavras-chave: Bentonita, Amido, PVA, GMA, Compósitos.

\section{ABSTRACT}

Films constituted by cassava starch, polyvinyl alcohol (PVA) and Bentonite clay (BNT) and glycerol as plasticizer were obtained using the casting method. In order to increase the compatibility of the polymers with the mineral and its hy- 
drophobicity, they were subsequently chemically modified by replacing the hydroxyl groups with vinyls using glycidyl methacrylate (GMA). This procedure generated films with excellent water sorption stability and $15 \%$ lower water vapor permeability. This strategy also resulted in a $25 \%$ improvement in tensile strength, maintaining the same Young's modulus and slight decrease in thermal stability (onset of degradation $14^{\circ} \mathrm{C}$ lower). The addition of BNT clay generates composite films with different mechanical, thermal and physical properties, however, there is a dependence between the amount of reinforcement and the structural distribution of the clay lamellae in the matrix. The chemical modifications were confirmed by H 1 NMR, FTIR, XRD and the films were characterized by XRD, sorption and water permeability, mechanical tests (traction, stretching and Young's modulus) and TGA. The use of $1 \% \mathrm{w} / \mathrm{w}$ of this reinforcement generates composites with structurally exfoliated BNT, independently of the previous modification with glycidyl methacrylate. The formulation with $5 \% \mathrm{~m} / \mathrm{m}$ generated intercalated composite films. Any other reinforcing content exhibits agglomerated (packaged) lamellar structures. It is noteworthy that in the formulations reinforced with $1 \%$ clay, there was an improvement of about $30 \%$ in tensile strength with $60 \%$ lower water permeability, for higher clayey loads. These facts indicate that the modifications proposed in this work have generated promising properties for the production of biodegradable packaging materials.

Keywords: Bentonite, Starch, PVA, GMA, Composites.

\section{INTRODUÇÃO}

A poluição ambiental e a deterioração ecológica causadas pelo amplo uso de polímeros sintéticos à base de petróleo são fontes de crescente preocupação global devido a sua característica inativa ao ataque de microorganismos.[1] Dessa forma, faz-se necessária uma busca por alternativas mais sustentáveis desenvolvendo materiais feitos totalmente ou parcialmente de polímeros renováveis e naturais, como celulose, amido e proteínas, os quais apresentam menores riscos ambientais, renovabilidade e menor custo.[2, 3,4$]$

Dentre estes, o amido é um dos biopolímeros com biodegradabilidade inerente, disponibilidade abundante e baixo custo, contudo este é altamente permeável a gases, extremamente higroscópico e gera filmes quebradiços. Ele pode ser combinado com o álcool polivinílico (PVA) a fim de melhorar suas propriedades mecânicas e de formação de filme para atender às necessidades das indústrias de embalagens plásticas. [5, 6]. O PVA é um polímero sintético biodegradável usado na indústria de embalagens devido às suas propriedades de formação de filme, cristalinidade e boas propriedades mecânicas. Entretanto, os filmes e compósitos mistos de PVA/amido continuam apresentando limitações com relação a sua utilização, especialmente por não atuarem como barreira à água devido à presença dos grupos hidroxila tanto no amido quanto no PVA. Também deixam a desejar por apresentarem baixa resistência mecânica à tração ao alongamento. [7, 8]

Com a finalidade de resolver estes problemas, muitos estudos têm buscado estratégias para tornarem estes polímeros menos higroscópicos, tais como: enxertia, acetilação, butirilação, reticulação, irradiação. [9, 10, 11]. Neste cenário, a reticulação da matriz polimérica tem sido empregada com vários agentes de reticulação a fim de tornar tais polímeros mais hidrofóbicos, como por exemplo epicloridrina [12], trimetafosfato de sódio [13], resorcinol-formaldeído [14], poli (metil-co-metacrilato) [15] e metacrilato de glicidila (GMA) [10]. Este último é um dos agentes de reticulação que vem sendo mais empregado nos últimos anos devido aos grupos éster e epóxi em sua estrutura, os quais reagem com os grupos hidroxila presentes no amido e PVA inserindo grupamentos vinilícos na estrutura dos polímeros orgânicos. Este processo pode desencadear reações de polimerização radicalares, iniciadas por persulfato de sódio, tanto em meio aquoso quanto no estado fundido. [16, 17] As propriedades mecânicas dos filmes de PVA/amido podem ser otimizadas pela incorporação de partículas inorgânicas tais como sílica [18], nanotubos de carbono [19], grafeno [20] e filosilicatos (argilas) [21], sendo que estas últimas, devido à variedade e ao incremento em outras características tais como, estabilidade térmica, baixa permeabilidade a gases, água, elevada resistência química e retardo a propagação de chamas. [3, 4, 22, 23, 24]

No entanto, várias dessas aplicações só são possíveis após a separação das camadas lamelares da argila uma das outras, visto que as argilas; naturais; exibem uma maior tendência a aglomerar-se em matrizes de amido /PVA e formar microcompósitos convencionais com propriedades precárias. A modificação orgânica, por meio do metacrilato de glicidila, poderia aumentar o espaçamento interlamelar $\left(\mathrm{d}_{001}\right)$, alterar as propriedades da superfície favorecendo a intercalação ao polímero ou mesmo a formação de nanocompósitos altamente esfoliados e imobilizados na matriz polimérica melhorando as características mecânicas de resistência a tração e de barreira a água. [3, 4, 22, 23-25]

Estudos sobre a ligação química de reforços inorgânicos em polímeros biodegradáveis são limitados na literatura, pois a maioria relata somente a ligação física entre estes ou se restringem somente aos polímeros da matriz dos compósitos. Sendo assim, este trabalho teve como objetivo realizar a modificação química do amido, PVA e da argila Bentonita (BNT) por meio da reação com metacrilato de glicidila e avaliar suas propriedades físicas, mecânicas, térmicas e morfológicas dos compósitos contendo $1 \%, 5 \%$ e $10 \%(\mathrm{~m} / \mathrm{m})$ de BNT. 


\section{MATERIAIS E MÉTODOS}

\subsection{Materiais}

Foram utilizados: amido de mandioca (Inpal Ind. Químicas, São Tomé PR); hidróxido de sódio P.A (Vetec Química Fina, Duque de Caxias, RJ); argila bentonita (Aliança Latina Ind. E Com. Ltda, Uruguaiana, RS); álcool etílico absoluto P.A (F.Maia, São Paulo, SP); acetona P.A (F.Maia, São Paulo, SP); metacrilato de glicidila C.G (Sigma - Aldrich, St Louis, EUA); persulfato de sódio P.A (Vetec Química Fina, Duque de Caxias, RJ); dimetilsulfóxido (DMSO) P.A (F.Maia, São Paulo, SP); água destilada e deionizada; álcool polivinílico Mw 89000 - 98000, 99 \% hidrolisado (Sigma - Aldrich, St Louis EUA); glicerol P.A (F.Maia, São Paulo, SP).

\subsection{Modificação química da BNT com GMA}

Previamente a modificação, $5 \mathrm{~g}$ de argila foi calcinada a $350{ }^{\circ} \mathrm{C}$ por $1 \mathrm{~h}$, para retirar quaisquer resquícios de matéria orgânica, e mantida em dessecador por 24 horas.

A suspensão modificadora de BNT de $\mathrm{pH}$ 10,5 foi preparada de acordo com a seguinte metodologia: 2,5 g de BNT bruto foram adicionados a $200 \mathrm{~mL}$ de uma solução aquosa, aquecidos até $65^{\circ} \mathrm{C}$ e agitados durante $1 \mathrm{~h}$. Depois disso, utilizou-se $6 \mathrm{~mL}$ de solução de $\mathrm{NaOH} 2 \mathrm{~mol} \mathrm{~L}^{-1}$ para se obter um $\mathrm{pH}$ de 10,5. Em seguida, $1 \mathrm{~mL}$ de GMA foi misturado na suspensão mineral por uma agitação constante e vigorosa durante $24 \mathrm{~h}$. O produto foi então filtrado sob vácuo e lavado com etanol. O produto final, chamado de BNT-m, foi liofilizado a $-55^{\circ} \mathrm{C}$ durante $24 \mathrm{~h}$.

\subsection{Modificação química do amido e do PVA com GMA}

Cinco gramas de amido foram dissolvidos em $100 \mathrm{~mL}$ de solução $50 / 50$ v/v água, DMSO a $90{ }^{\circ} \mathrm{C}$ durante $1 \mathrm{~h}$. Depois disso, a solução de $\mathrm{NaOH} 0,1 \mathrm{~mol} \mathrm{~L}^{-1}$, foi gotejada até que a solução atingisse o pH de 10,5. Em seguida, adicionou-se $2 \mathrm{~mL}$ de GMA, que reagiu com o amido por $24 \mathrm{~h} \mathrm{a} 65^{\circ} \mathrm{C}$. Após este período, precipitou-se o polissacárido modificado, chamado de amido-m, em $250 \mathrm{~mL}$ de etanol, e filtrava-se sob vácuo. Finalmente, o precipitado foi congelado em $\mathrm{N}_{2}$ líquido e liofilizado durante $24 \mathrm{~h}$.

O mesmo processo foi utilizado na modificação do PVA, contudo utilizou-se solução 90/10 v/v, água DMSO e precipitou-se o PVA com acetona. O sólido obtido foi chamado de PVA-m.

\subsection{Preparação dos filmes compósitos de amido/PVA/BNT}

Em $25 \mathrm{ml}$ de água deionizada uma dispersão de BNT-m foi preparada adicionando 1,5 ou $10 \% \mathrm{~m} / \mathrm{m}$, em relação à massa dos polímeros; (respectivamente $0,025 \mathrm{~g}, 0,125 \mathrm{~g}$ e $0,25 \mathrm{~g}$ ) e mantida sobe agitação vigorosa por $24 \mathrm{~h}$ à temperatura ambiente.

Em outra solução foram dispersos 2,25 g de amido-m e 0,25 g de PVA-m em $25 \mathrm{~mL}$ de água deionizada e gelatinizados a $80^{\circ} \mathrm{C}$ durante 30 min por agitação mecânica (1000 rpm) contínua. A dispersão BNT-m preparada previamente foi adicionada lentamente à esta solução e mantida sob agitação por $1 \mathrm{~h}$ a $80^{\circ} \mathrm{C}$. Em seguida, adicionou-se $1 \mathrm{~g}$ de glicerol e $0,046 \mathrm{~g}$ de persulfato de sódio mantendo a agitação durante mais $30 \mathrm{~min}$. Por fim, a solução foi vertida sobre placas de Teflon com $85 \mathrm{~mm}$ de diâmetro e secadas a $50{ }^{\circ} \mathrm{C}$ durante $24 \mathrm{~h}$. Os filmes foram removidos e equilibrados em $23{ }^{\circ} \mathrm{C}$ e $53 \%$ de umidade relativa antes dos ensaios mecânicos.

Para efeito comparativo, foram preparados filmes compósitos com as mesmas porcentagens de reforço utilizando amido, PVA e argila BNT sem a modificação química com GMA. A Tabela 1 apresenta a composição dos materiais estudados.

Tabela 1: Composição dos materiais estudados.

\begin{tabular}{c|c|c|c|c}
\hline AMOSTRA & \% Amido (massa) & \% PVA (massa) & $\begin{array}{c}\text { \% BNT ( em relaçãoa } \\
\text { massa dos polímeros ) }\end{array}$ & modificados com GMA \\
\hline $\mathrm{Cm}$ & 90,00 & 10,00 & 0,00 & $\operatorname{Sim}$ \\
\hline $\mathrm{C} 1 \% \mathrm{~m}$ & 90,00 & 10,00 & 1,00 & $\mathrm{Sim}$ \\
\hline $\mathrm{C} 5 \% \mathrm{~m}$ & 90,00 & 10,00 & 5,00 & $\mathrm{Sim}$ \\
\hline
\end{tabular}




\begin{tabular}{c|c|c|c|c}
\hline $\mathrm{C} 10 \% \mathrm{~m}$ & 90,00 & 10,00 & 10,00 & Sim \\
\hline $\mathrm{C}$ & 90,00 & 10,00 & 0,0 & - \\
\hline $\mathrm{C} 1 \%$ & 90,00 & 10,00 & 1,0 & - \\
\hline $\mathrm{C} 5 \%$ & 90,00 & 10,00 & 5,0 & - \\
\hline $\mathrm{C} 10 \%$ & 90,00 & 10,00 & 10,0 & - \\
\hline
\end{tabular}

\subsection{Caracterizações}

Os espectros de infravermelho foram obtidos utilizando-se um espectrofotômetro de infravermelho com transformada de Fourier (FT-IR), Bomem modelo MB 100. Todas as análises foram realizadas em triplicata na região de 4000 a $400 \mathrm{~cm}^{-1}$ obtendo 128 varreduras com resolução de $4 \mathrm{~cm}^{-1}$.

Os difratogramas de raios-X (DRX); foram obtidos através de um difratômetro de Raios-X SHIMADZU XRD 6000, operando com uma resolução de $2^{\circ} \mathrm{min}^{-1}$ no intervalo de varredura $2 \theta$ de 1 à $50^{\circ}$. As análises foram efetuadas utilizando uma radiação de $\mathrm{Cu} \mathrm{K} \alpha(\lambda=0,15406 \mathrm{~nm})$ e filtro de $\mathrm{Ni}$ sob uma aceleração de $40 \mathrm{kV}$ e uma corrente de $30 \mathrm{~mA}$. O espaçamento basal $\left(\mathrm{d}_{001}\right)$ das amostras foram calculados pela equação 1

$$
\mathrm{n} \lambda=2 \mathrm{~d} \operatorname{sen} \theta
$$

Sendo: $\theta$ é o ângulo de difração utilizado, $\lambda$ é o comprimento de onda da radiação de raios-X, $\mathrm{n}$ é a distância do espaçamento.

Os espectros de Ressonância Magnética Nuclear de Hidrogênio (RMN de ${ }^{1} \mathrm{H}$ ) foram obtidos em espectrômetro Varian, modelo Mercury Plus BB, $300 \mathrm{MHz}$, operando a 300,059 MHz. Para a obtenção dos espectros dos polímeros, as amostras foram solubilizadas em DMSO com $0,05 \%$ de 3-(trimetil -silil) propionato de sódio 2,2,3,3 - d4 (TPS), como referência interna. Foram utilizadas sequências de pulsos padrões, para o núcleo de hidrogênio: largura de pulso de $90^{\circ} \mathrm{e}$ tempo de reciclagem entre pulsos (d1) de 30s. Os espectros obtidos para o metacrilato de glicidila foram obtidos utilizando o clorofórmio deuterado $\left(\mathrm{CDCl}_{3}\right)$ contendo $0,05 \%$ de tetrametilsilano (TMS) como referência interna.

Os filmes de amido/PVA/BNT foram cortados em tiras $\left(150 \mathrm{~mm}\right.$ x $70 \mathrm{~mm}$ ) e climatizados à temperatura de $25 \pm 3{ }^{\circ} \mathrm{C}$ e umidade relativa de $55 \pm 3 \%$ por $48 \mathrm{~h}$ antes do ensaio. As propriedades mecânicas dos filmes foram obtidas seguindo a norma ASTM D882-02 [20], utilizando um analisador de textura TA-XT2i (Stable Micro System Company, Reino Unido). A separação inicial foi de $50 \mathrm{~mm}$ e a velocidade de tração foi de $0,8 \mathrm{~mm} \cdot \mathrm{s}^{-1}$. As propriedades de tração determinadas foram: tração na ruptura (MPa), alongamento na ruptura (E\%) e módulo de Young (MPa) os quais foram determinados diretamente utilizando o software Texture Expert V.1.15 da Stable Microsystems.

Os corpos de prova $(25 \mathrm{~mm} \times 25 \mathrm{~mm})$ foram secos em estufa a $50{ }^{\circ} \mathrm{C}$ até obter massa constante e aguardaram $24 \mathrm{~h}$ em dessecador para atingir equilíbrio térmico. Estes foram colocadas em funil de vidro sinterizado $\mathrm{n}^{\circ} 0$ e em seguida foram pesados. O sistema amostra + funil, foi imerso em Becker de $500 \mathrm{~mL}$, contendo $200 \mathrm{~mL}$ de água destilada. O intumescimento dos filmes foi monitorado em intervalos de $15 \mathrm{em} 15 \mathrm{~m}$ durante $6 \mathrm{hs}$. A taxa de absorção de água (I) foi calculada conforme a equação 2 :

$$
I(\%)=\frac{m-m o}{m o} \times 100
$$

Sendo $\mathrm{m}=$ massa final e $\mathrm{mo}=$ massa inicial .

A permeabilidade ao vapor de água (WVP) dos filmes foram realizadas conforme o método ASTM E96-00. [26] (Figura 1). Resumidamente os filmes foram cortados em corpos de prova circulares de $4,0 \mathrm{~cm}$ de diâmetro e dispostos em cápsulas de teflon, fixados com anéis de alumínio (Figura 1A). Dentro das capsulas colocou-se sílica gel previamente secas em estufa a $105^{\circ} \mathrm{C}$ e resfriadas em dessecador por $24 \mathrm{~h}$ e inseridas no interior das células (Figura 1B). As células de permeação foram colocadas dentro de dessecador contendo água destilada a fim de garantir umidade relativa de $100 \%$ (Figura 1C). A massa do sistema (célula + filme) foi determinada em balança analítica em intervalos de uma hora durante $6 \mathrm{~h}$. Os ensaiosforam realizados em triplicata. O procedimento utilizado para a determinação da permeabilidade é realizado pela passagem de vapor de água através do filme e absorção pela sílica gel seca, o qual produz aumento de massa que é expresso em gramas de água por metro quadrado do corpo de prova, por unidade de tempo, que se convenciona denominar de "Taxa de Permeabilidade ao Vapor de água" - WPA - [m (água)/(m².h)], de acordo com a equação 3. 


$$
\mathrm{WPA}=\frac{G}{t \cdot A}
$$

Onde G/t representa o coeficiente angular da reta obtida por regressão linear do gráfico de ganho de massa $(\mathrm{g}) \mathrm{em}$ função do tempo de acondicionamento (h) e A é a área de permeação de cada corpo de prova.

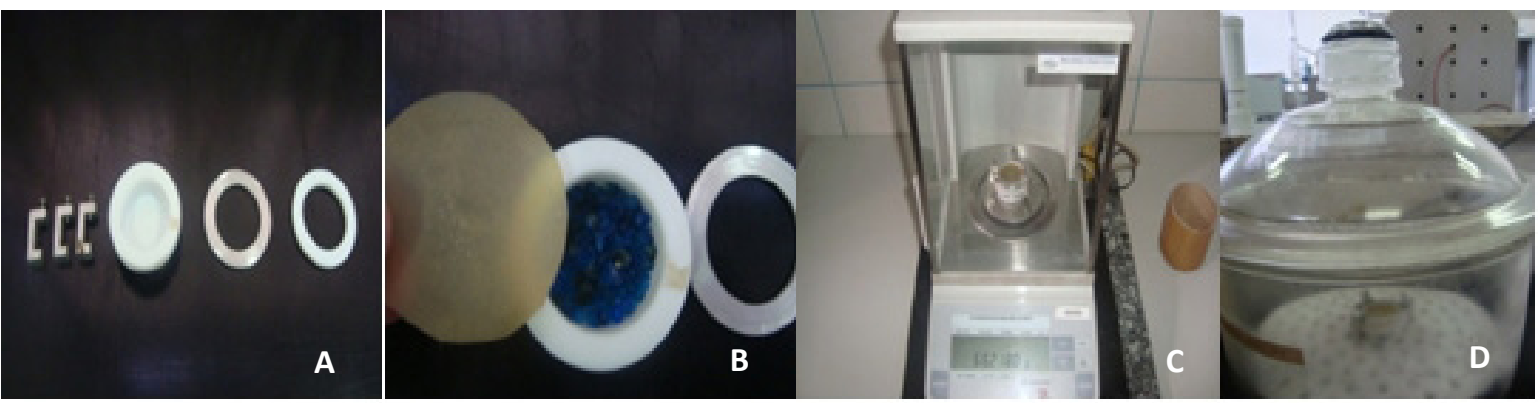

Figura 1: Esquema para o ensaio de permeabilidade ao vapor de água

As análises termogravimétricas dos compósitos foram obtidas em um analisador Netzsch modelo STA 409 PG/4/G Luxx, sob fluxo de nitrogênio com vazão de $20 \mathrm{~mL} \mathrm{~min}^{-1}$. Todas as amostras foram aquecidas em intervalo de temperatura de $25^{\circ} \mathrm{C}$ a $900{ }^{\circ} \mathrm{C}$, com taxa de aquecimento de $10^{\circ} \mathrm{C} \mathrm{min}^{-1}$.

\section{RESULTADOS E DISCUSSÃO}

\subsection{Caracterizações da modificação química da BNT-m}

A Figura 2 apresenta os difratogramas de raios-X da BNT e BNT-m, no intervalo $2 \theta=3-12^{\circ}$. O sinal de difração obtido para a BNT, corresponde ao plano $\mathrm{d}_{001}$ e foi detectado em $2 \theta=9,13^{\circ}$ equivalente a uma espaçamento interlamelar, calculado pela lei de bragg, de $\mathrm{d}_{001}=9,72 \AA$. Após a reação de modificação química do argilomineral com o GMA, houve o deslocamento desse pico a $2 \theta=6,05^{\circ}$ o qual equivale a um espaçamento de $\mathrm{d}_{001}=14,62 \AA$. Quando se compara o espaçamento interlar da BNT a BNT-m, nota-se claramente que a reação com metacrilato de glicidila causa uma alteração na estrutura da argila a qual, provavelmente, deve-se à inserção de moléculas de GMA na estrutura multicamada formadora da BNT. Com o aumento do espaçamento interlamelar há a diminuição da atração eletrostática entre as camadas lamelares, permitindo que uma maior quantidade de água penetre entre elas e seja adsorvida, de forma que esta seja totalmente esfoliada e dispersa no líquido favorecendo assim o emprego da técnica de casting.

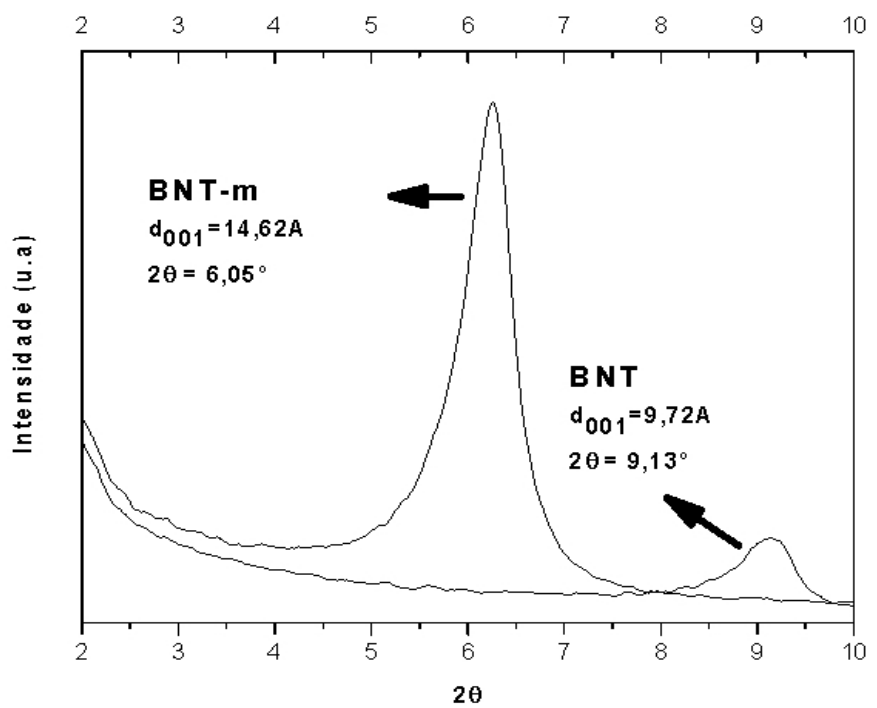

Figura 2: Difratogramas de raios-X das amostras, BNT e BNT-m 
Espectros de FT-IR do metacrilato de glicidila (GMA), argila bentonita (BNT) e da argila bentonita modificada (BNT$-\mathrm{m})$, são exibidos na Figura 3. No espectro do metacrilato de glicidila podem ser atribuídas bandas referentes aos seguintes grupamentos: estiramento vibracional de carbonila $\mathrm{C}=\mathrm{O}\left(1720 \mathrm{~cm}^{-1}\right)$, estiramento vibracional da ligação $\mathrm{C}=\mathrm{C}\left(1635 \mathrm{~cm}^{-1}\right)$, do estiramento anel epóxido $\left(1255 \mathrm{~cm}^{-1}\right)$, deformação assimétrica do anel epóxido $\left(908 \mathrm{~cm}^{-1}\right)$, deformação simétrica do anel epóxido $\left(845 \mathrm{~cm}^{-1}\right)$ deformação fora do plano $\mathrm{R}_{2} \mathrm{C}=\mathrm{CH}_{2}\left(946 \mathrm{~cm}^{-1}\right)$ e estiramento $\mathrm{C}-\mathrm{O}$ de éster $\left(1170 \mathrm{~cm}^{-1}\right)$. $[10,16,17]$

Nota-se, nos espectros da argila e da argila modificada quimicamente (BNT e BNT-m) com o metacrilato de glicidila duas bandas intensas respectivamente em: $3625 \mathrm{~cm}^{-1}$ e em $3426 \mathrm{~cm}^{-1}$ referentes ao estiramento vibracional de grupamentos $\mathrm{O}-\mathrm{H}$ derivados respectivamente a água fracamente e fortemente ligada na estrutura do aluminossilicato.

Para a argila modificada (BNT-m) há o aparecimento da banda em $1720 \mathrm{~cm}^{-1}$ correspondentes ao estiramento vibracional dos grupamentos $\mathrm{C}=\mathrm{O}$ proveniente da ligação química do GMA na estrutura do mineral. A banda de maior intensidade em $1045 \mathrm{~cm}^{-1}$ corresponde ao estiramento do grupamento $\mathrm{Si}-\mathrm{O}$ proveniente da estrutura química dos silicatos presentes nas argilas [투 $]$. Nota-se que não há sinais referentes aos grupamentos do anel epóxi nos espectros da BNT-m. Esta ausência destaca que a inserção do grupamento metacrilato na estrutura do material se deu via transesterificação e eliminação do grupamento glicidila, conforme mecanismo estudado por REIS et al. [10]. Este resultado corrobora com a alteração no espaçamento interlamelar, da BNT e BNT-m, evidenciado nos difratogramas de raio-X, cujo aumento corresponde a inserção de uma molécula pequena tal como o metacrilato, o qual pode se ligar a outras estruturas via reação radicalar de adição ou a polímeros funcionalizados com grupamentos vinílicos, promovendo interações químicas entre tais materiais, ao invés de meras interações físicas.

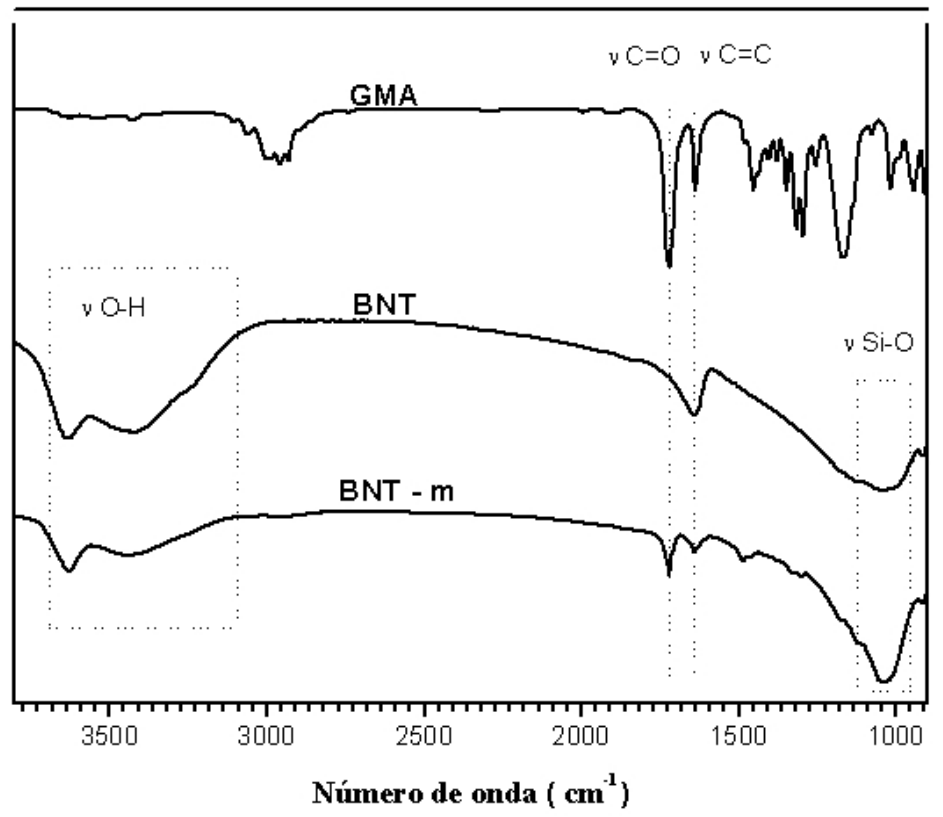

Figura 3: Espectros de FT-IR das amostras, BNT e BNT-m, obtidos entre 4000 a $400 \mathrm{~cm}^{-1}$.

\subsection{Caracterizações da modificação química do Amido e PVA.}

Uma vez que a modificação da argila foi realizada com sucesso, a próxima etapa foi promover a modificação dos polímeros. A Figura 4 exibe os espectros de RMN de ${ }^{1} \mathrm{H}$ do amido, amido-m e GMA na faixa espectral de 7,0-0 ppm. Os sinais exibidos em 6,17 ppm e 5,64 ppm no espectro do amido-m são atribuídos aos hidrogênios ligados ao carbono vinílico originados do metacrilato de glicidila. O sinal em 1,96 ppm no mesmo espectro é atribuído aos três hidrogênios em um grupo metílico, os quais estão ligados a um carbono vinílico, presentes também no espectro do GMA. Pode-se ainda destacar a ausência de picos relativos aos grupamentos gerados pela abertura do anel epóxi, esperados em 5,06, 3,73 e 4,27 ppm do substituinte glicidila, novamente, Segundo REIS et al. [10], o não aparecimento destes sugere que reação ocorreu por transesterificação, a qual é mais suscetível em pH alcalino. [10,17] 


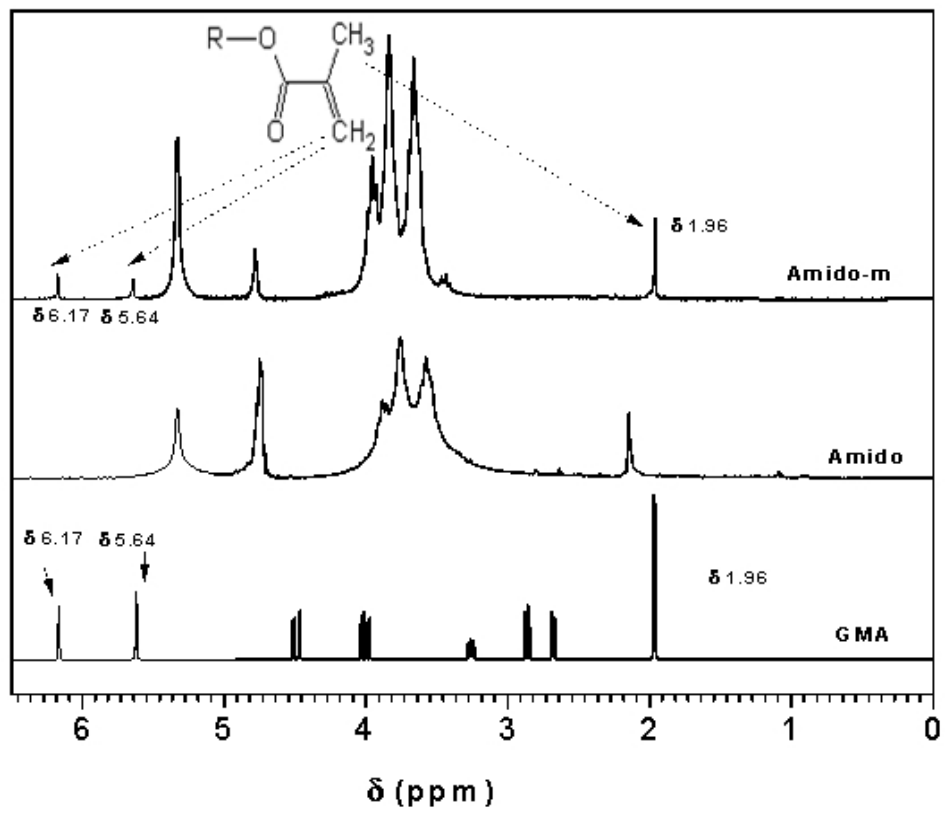

Figura 4: Espectros de $\mathrm{RMN}{ }^{1} \mathrm{H}$ das amostras de Amido-m, Amido e GMA.

Comportamento similar ocorre ao analisar a Figura 5: os espectros do PVA-m apresentam os mesmo sinais, em 6,06 ppm e 5,65 ppm e em 1,97 ppm. Estes sinais comprovam que houve a inserção do grupamento metacrilato no polímero, e que tal reação ocorreu por meio da transesterificação do metacrilato de glicidila.

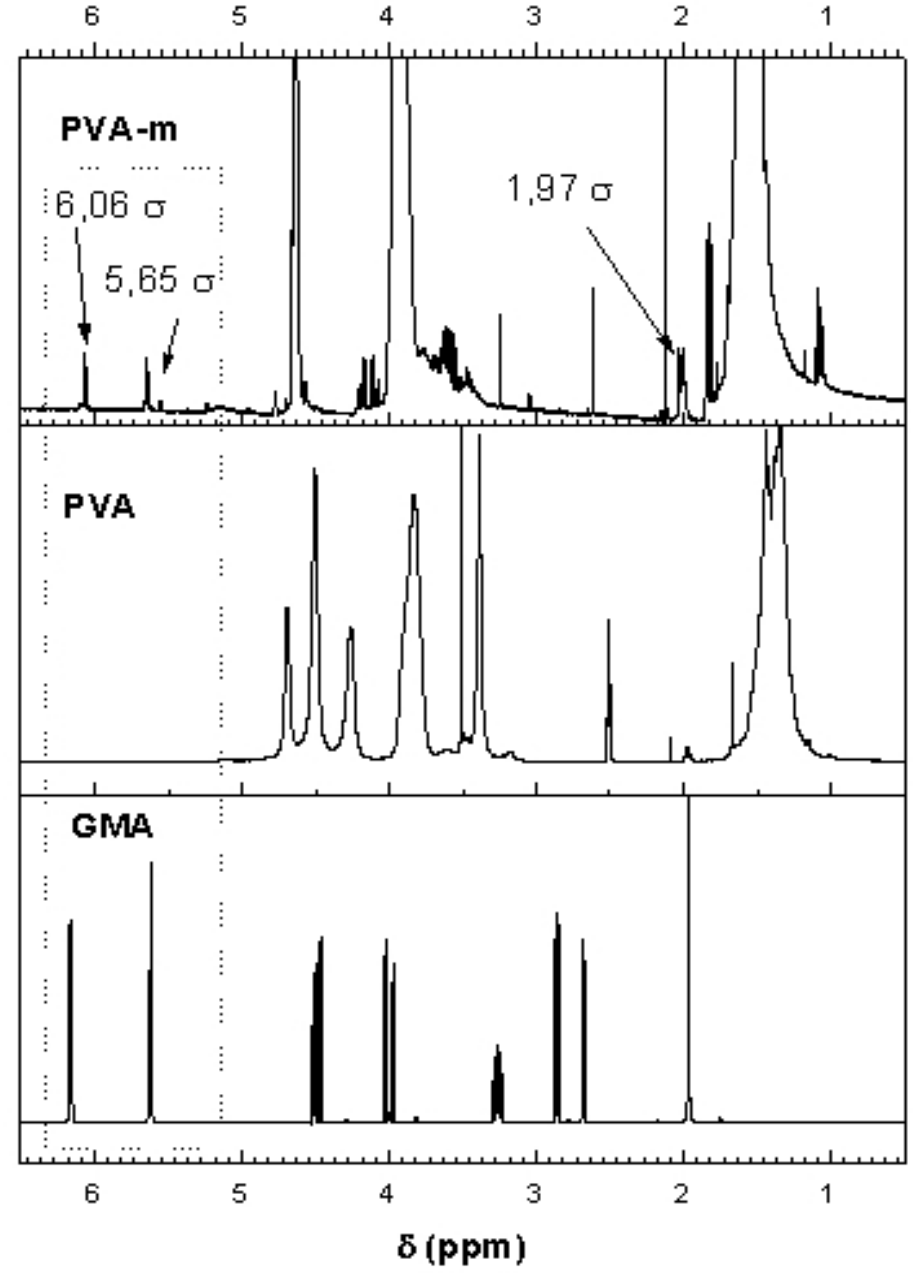

Figura 5: Espectros de $\mathrm{RMN}{ }^{1} \mathrm{H}$ das amostras de PVA-m, PVA e GMA. 


\subsection{Caracterizações dos filmes compósitos.}

\subsubsection{Difração de raios-X}

Após a inserção de grupamentos vinílicos em todos os materiais de precursores (BNT, PVA e amido), pode - se preparar filmes compósitos mistos através da reticulação destes durante a etapa de casting utilizando persulfato de sódio como iniciador.

Os difratogramas dos compósitos de PVA/amido/BNT sem a modificação química com GMA são mostrados na Figura 6. Um pico estreito em $2 \theta=9,13^{\circ}$ característico da BNT, é atribuído ao espaçamento basal de $\mathrm{d}_{001}=9,74 \AA$ calculado através da equação de Bragg. Não foram observados picos de difração em $2 \theta=3-10^{\circ}$ para os filmes contendo somente PVA/amido, indicando que não existe estrutura cristalina nesse intervalo. Para compósitos com $1 \%$ de BNT, o pico de difração do espaçamento $\left(\mathrm{d}_{001}\right)$ desapareceu, sugerindo que houve a formação de um nanocompósito contendo uma estrutura altamente esfoliada da argila, formada por camadas lamelares únicas dispersas de maneira homogênea e desordenada (amorfa). Contudo, para as formulações contendo 5\% e 10\% do reforço, nota-se que há o reaparecimento deste halo, neste caso para tais formulações há a obtenção somente de um microcompósito onde as lamelas de BNT se encontram agrupadas e dispersas na matriz polimérica. Segundo TIAN et al. [24] tal aglomeração reflete em propriedades mecânicas inferioresquando comparadas com os materiais nanocompósitos.

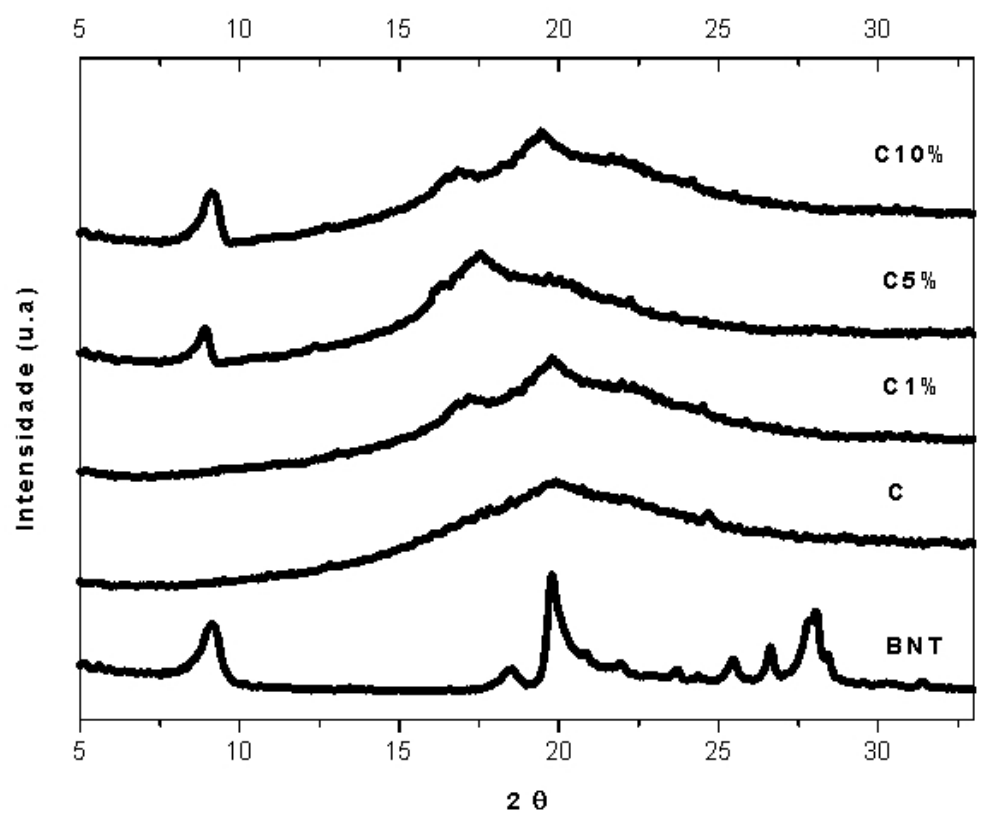

Figura 6: Difratogramas de raio-X, para as amostras BNT, C, C1\%, C5\% e C10\%.

Dentre as amostras modificadas com metacrilato de glicidila as composições com 1 e $10 \%$ do reforço não apresentaram modificação (Figura 7) nos difratogramas em relação aos compósitos não modificados. Entretanto, para a amostra contendo $5 \%$ de reforço há o deslocamento do halo para região de baixo ângulo (menor que $2 \theta=3^{\circ}$ ) indicando que houve além da esfoliação o fenômeno da intercalação das lamelas devido a inserção da molécula orgânica proveniente do GMA. Assim, pode-se afirmar que o amido-m e as macromoléculas de PVA-m entraram entre as lamelas da BNT-m e ampliaram o espaçamento das camadas de BNT-m, promovendo a intercalação do argila no compósito [1, 2, 16]. 


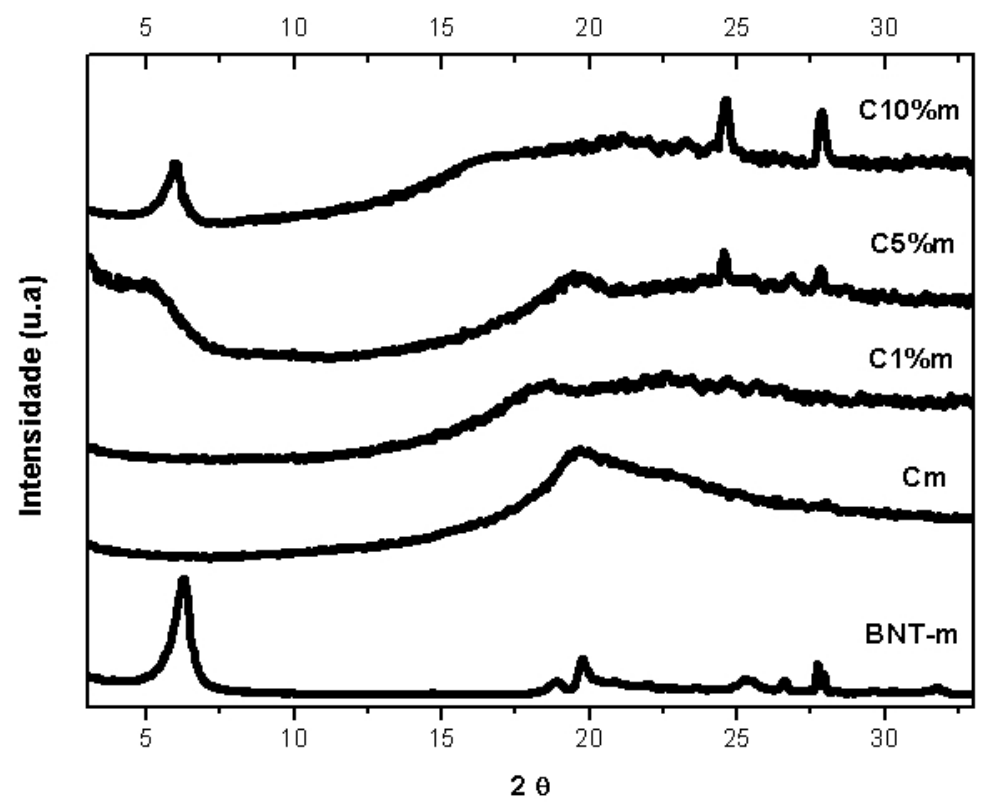

Figura 7: Difratogramas de raio-X, para as amostras BNT-m, Cm, C1\%m, C5\%m e C10\%m.

\subsubsection{Ensaio mecânico sob tração}

O comportamento mecânico dos materiais pode ser marcado pela resposta que apresenta frente a ação de uma força. Quando uma força é exercida sobre um corpo sólido, este tenderá a sofrer uma deformação. Na Tabela 2 está apresentado o resultado do limite de resistência à tração, módulo de Young e alongamento na ruptura dos compósitos para os corpos de prova PVA/amido/BNT sob diferentes formulações em ambiente controlado de umidade relativa e temperatura..

Tabela 2: Valores das propriedades mecânicas apresentadas pelo ensaio de tração nas amostras.

\begin{tabular}{c|c|c|c}
\hline AMOSTRA & $\begin{array}{c}\text { RESISTÊNCIA À } \\
\text { TRAÇÃO (MPA) }\end{array}$ & $\begin{array}{c}\text { ALONGAMENTO } \\
\text { MÁXIMO (E\%) }\end{array}$ & $\begin{array}{c}\text { MÓDULO DE } \\
\text { YOUNG (MPA) }\end{array}$ \\
\hline $\mathrm{C} m$ & $2,5 \pm 0,4$ & $150 \pm 16$ & 0,017 \\
\hline $\mathrm{C} 1 \% \mathrm{~m}$ & $3,6 \pm 0,4$ & $126 \pm 15$ & 0,029 \\
\hline $\mathrm{C} 5 \% \mathrm{~m}$ & $11 \pm 1,5$ & $42 \pm 6$ & 0,262 \\
\hline $\mathrm{C} 10 \% \mathrm{~m}$ & $25 \pm 0,3$ & $7 \pm 2$ & 3,571 \\
\hline $\mathrm{C}$ & $2,0 \pm 0,6$ & $184 \pm 2,6$ & 0,011 \\
\hline $\mathrm{C} 1 \%$ & $2,7 \pm 0,5$ & $155 \pm 13$ & 0,017 \\
\hline $\mathrm{C} 5 \%$ & $8,3 \pm 0,9$ & $65 \pm 3,6$ & 0,128 \\
\hline $\mathrm{C} 10 \%$ & $18 \pm 2,6$ & $9 \pm 3,7$ & 2,00 \\
\hline
\end{tabular}

É demonstrado que nanocompósitos de polímero-argila têm suas propriedades mecânicas melhoradas quando comparados ao polímero puro, sendo esse aumento gradual e diretamente proporcional ao incremento $(\mathrm{m} / \mathrm{m})$ nos valores da BNT nas amostras. Observa-se, comparativamente, que o resultado do limite de resistência à tração das amostras com modificação química por GMA aumentam, independentemente da quantidade de reforço, em média 32\% em relação a amostras que não sofreram essa a modificação química. Esse comportamento pode ser explicado pela imobilização das cadeias poliméricas decorrentes da modificação química, causando ligações covalentes entre os polímeros $[10,16,17]$ ou entre os polímeros e o reforço mineral [16]. Este aumento ocorre mesmo quando não há a completa esfoliação do reforço, conforme discutido na seção anterior. É importante destacar que tal resultado aumenta a gama de possíveis aplicações do material final, uma vez que o setor de embalagens necessita de materiais com diferentes propriedades mecânicas tais como resistência e flexibilidade.

Observou-se também aumento no módulo de Young e diminuição no alongamento na ruptura com o aumento do BNT nas formulações. Por exemplo, o módulo de Young aumentou de 0,017 MPa nas formulações contendo PVA/amido não re- 
forçados para 3,571 MPa na formulação contendo 10\% BNT-m. A baixa porcentagem de alongamento para as formulações contendo $10 \%$ de reforço de argila está muito próxima da saturação de reforço na matriz, evidenciando que o aumento da quantidade de reforço na matriz produz compósitos extremamente rígidos e quebradiços. É importante salientar que para os compósitos contendo 1 ou 5\% do reforço há diminuição na elasticidade em comparação com o material não tratado com GMA, porém seus valores são ainda satisfatórios, não caracterizando materiais quebradiços ou rígidos.

O ensaio de captação de água exibidos na Figura 8 mostrou a fragilidade dos biocompósitos não modificados quimicamente com metacrilato de glicidila, sendo que todas as formulações entraram em colapso (dissolveram-se) após aproximadamente 120 minutos de contato com a água. Tal comportamento deve-se a disponibilidade de grupamentos hidroxilas presentes no amido e PVA tornando os compósitos higroscópicos.

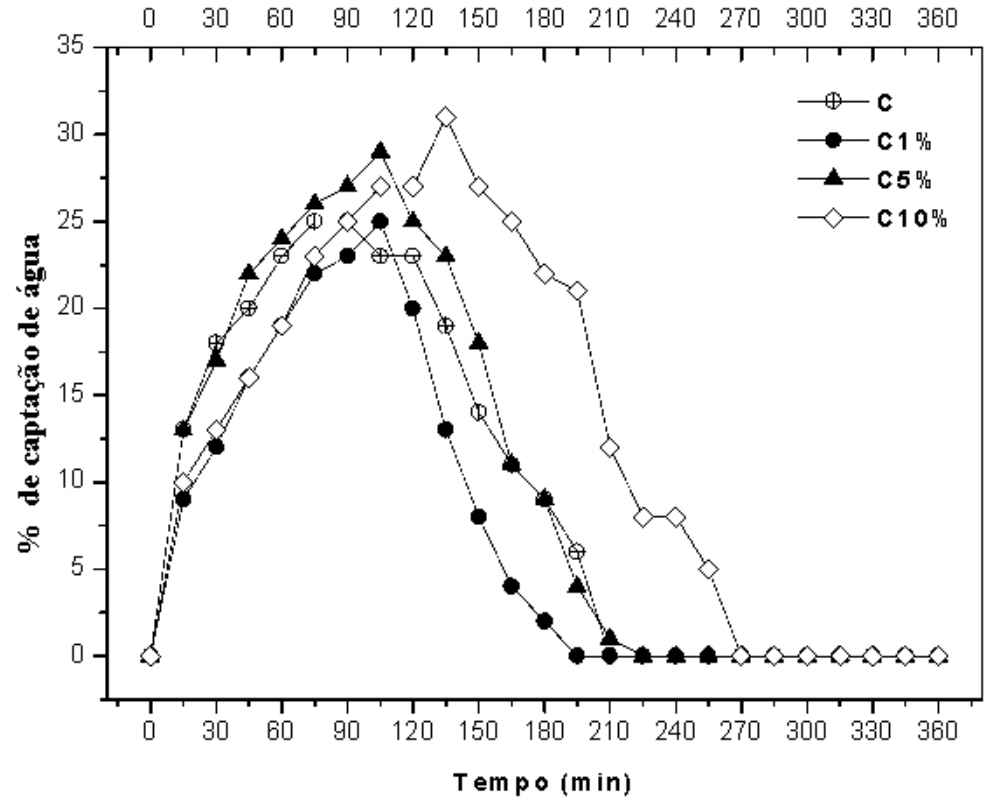

Figura 8: Porcentagem de captação de água para os compósitos, C, C1\%, C5\% e C10\%.

Por outro lado, os filmes reticulados mantiveram sua integridade na presença de água independentemente da quantidade de reforço aplicada. Isso pode ser explicado devido a uma estrutura mais compacta do filme reticulado, o que acarreta em menor absorção de água aliada ao aumento do caráter hidrofóbico devido à substituição dos grupamentos hidroxilas por grupamentos metacrioila. GUILHERME et al. [16] relatam que o mecanismo de intumescimento da água pode ser entendido como uma processo difusional, resultado das interações físico-químicas entre água e o compósito. Nossos dados demostram que a cinética de intumescimento é ligeiramente maior nos compósitos do que no filme contendo somente polímeros, tal comportamento deve-se a repulsão de cargas na superfície das lamelas do mineral, favorecendo a expansão do polímero e consequentemente permitindo a difusão nas redes poliméricas. Assim, ao absorver água, esta fica retida na estrutura do material compósito sem ocorrer à dissolução do mesmo de forma que a utilização de filmes a base de amido/ PVA e BNT quando modificados om metacrilato de glicidila permitem uma ampliação da aplicação dos mesmos, principalmente no que tange ao contato com água. 


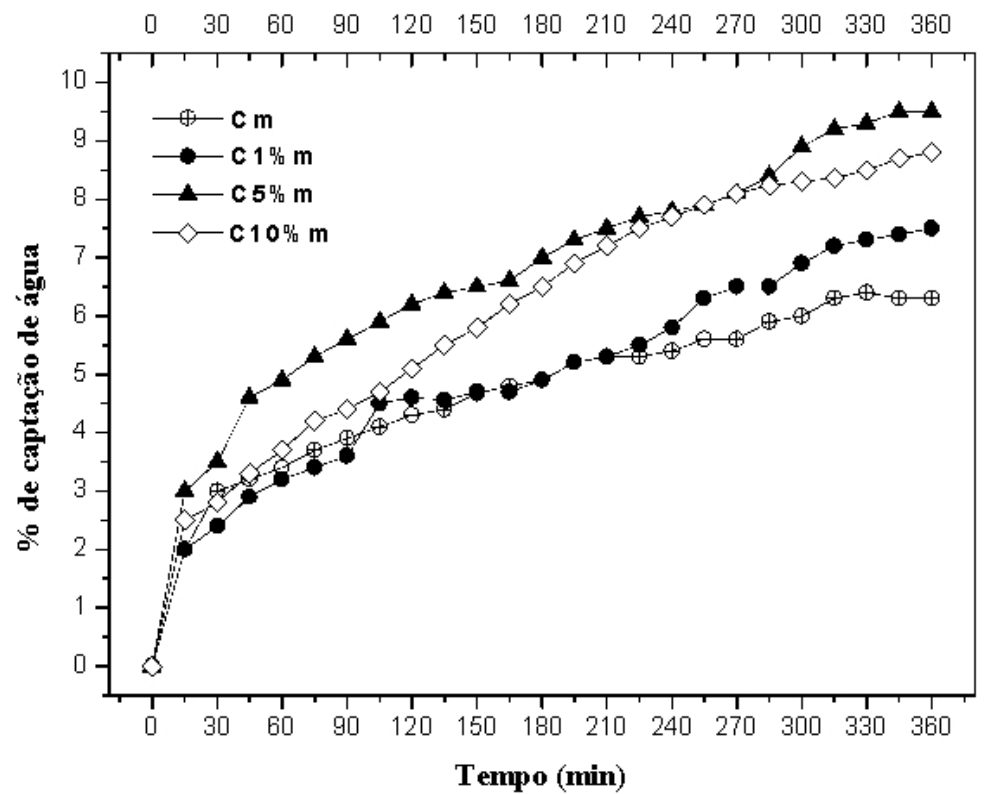

Figura 9: Porcentagem de captação de água para os compósitos, C, C1\%, C5\% e C10\%.

\subsubsection{Permeabilidade ao vapor de água (WVP).}

A Figura 10 ilustra os efeitos da adição de reforço e imobilização das cadeias poliméricas devido a reticulação. O filme contendo PVA/amido apresentou a maior taxa de permeabilidade $\left(5,80 \mathrm{~g} / \mathrm{m}^{2} . \mathrm{h}\right.$ ) diminuindo para 4,92 $\mathrm{g} / \mathrm{m}^{2} . \mathrm{h}$ (redução de 15\%) na mesma formulação, mas utilizando PVA-m/ amido-m. Segundo MITTAL et al. [8], tal comportamento deve-se a baixa mobilidade das cadeias poliméricas após a ligação química entre as matrizes.

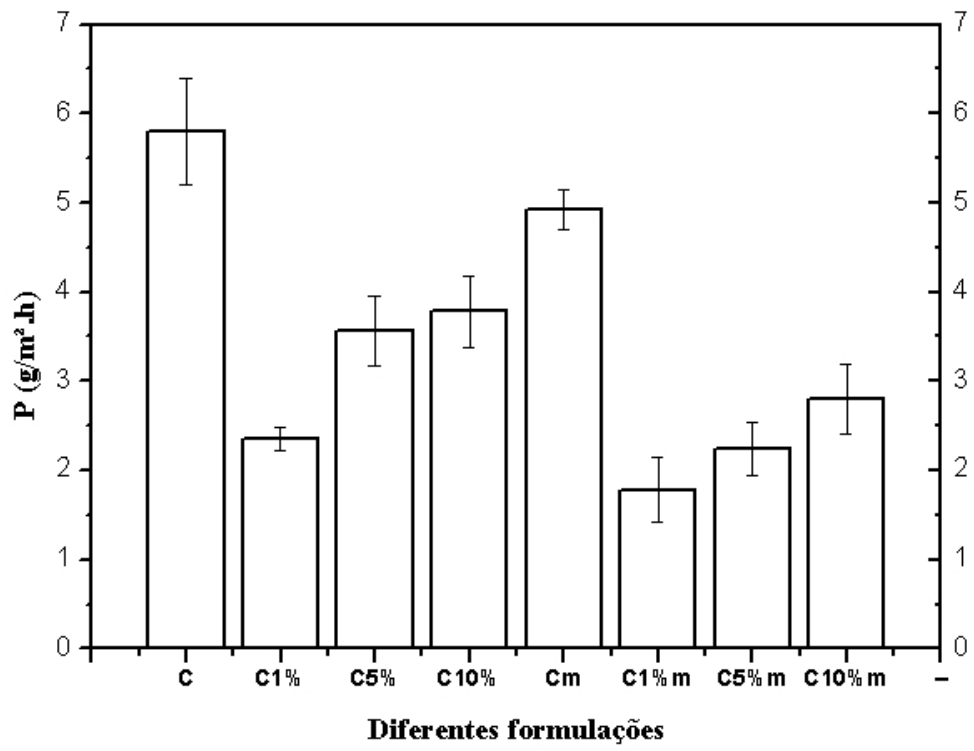

Figura 10: Ensaio de permeabilidade ao vapor d’água em diferentes formulações.

As formulações $\mathrm{C} 1 \% \mathrm{~m}, \mathrm{C} 1 \%$, e $\mathrm{C} 5 \% \mathrm{~m}$ apresentaram respectivamente as menores taxas de permeabilidade $(1,78$; 2,36 e $2,24 \mathrm{~g} / \mathrm{m}^{2}$.h, respectivamente). A esfoliação completa do reforço na matriz, conforme discutido na seção 3.3.1, diminuiu significativamente a permeabilidade ao vapor de água, pois cria barreiras para que as moléculas de água difundam-se através do filme. [8, 21] Para as formulações com o reforço mineral esta melhora foi de aproximadamente 35\%, mesmo com baixo nível de intercalação ou na presença de camadas aglomerada. Isso destaca que nossa proposta de modificação do material com GMA leva a um material muito menos permeável ao vapor d'água, comparativamente aos filmes tradicionais baseados em interações intermoleculares físicas; tal característica poderia ser muito explorada na área de embalagens alimentícias para frutas, hortaliças, carnes, queijos e vegetais, uma vez que ao diminuir permeabilidade consequentemente 
há menor desidratação, perda de peso, alterações físicas, químicas e organolépticas de alimentos com maiores valores de umidade.

\subsubsection{Análise Termogravimétrica}

As curvas TGA dos compósitos PVA/Amido/BNT e PVA-m/Amido-m/BNT-m são mostrados respectivamente nas Figuras 11 e 12 . A decomposição inicial que equivale a aproximadamente $15 \%$ da massa dos compósitos, a $230{ }^{\circ} \mathrm{C}$ deve-se principalmente a vaporização de voláteis, incluindo o plastificante (glicerol). [8, 24] As macromoléculas sofrem degradação em 290-330 ${ }^{\circ} \mathrm{C}$. Com o aumento da proporção de BNT-m, a estabilidade térmica dos compósitos elevou-se, visto que a quantidade de massa residual presente após a degradação dos polímeros é maior do que a formulação sem reforço algum, este fenômeno permaneceu até a temperatura de $1000^{\circ} \mathrm{C}$. Desta forma, sugere-se que quando aquecida a BNT rearranje-se em estruturas similares ao grafite. $\mathrm{O}$ material orgânico presente nas estruturas lamelares da argila também sofre o mesmo processo de organização ao invés de sofrer decomposição instantânea em $\mathrm{CO}_{2}$. Pode-se concluir então que a argila está atuando como uma barreira térmica para a transferência de calor nas cadeias poliméricas evitando que o calor se propague rapidamente retardando a degradação térmica aos polímeros. $[16,22]$ O restante da perda de massa relaciona-se a oxidação dos polímeros e a calcinação da argila. [22]

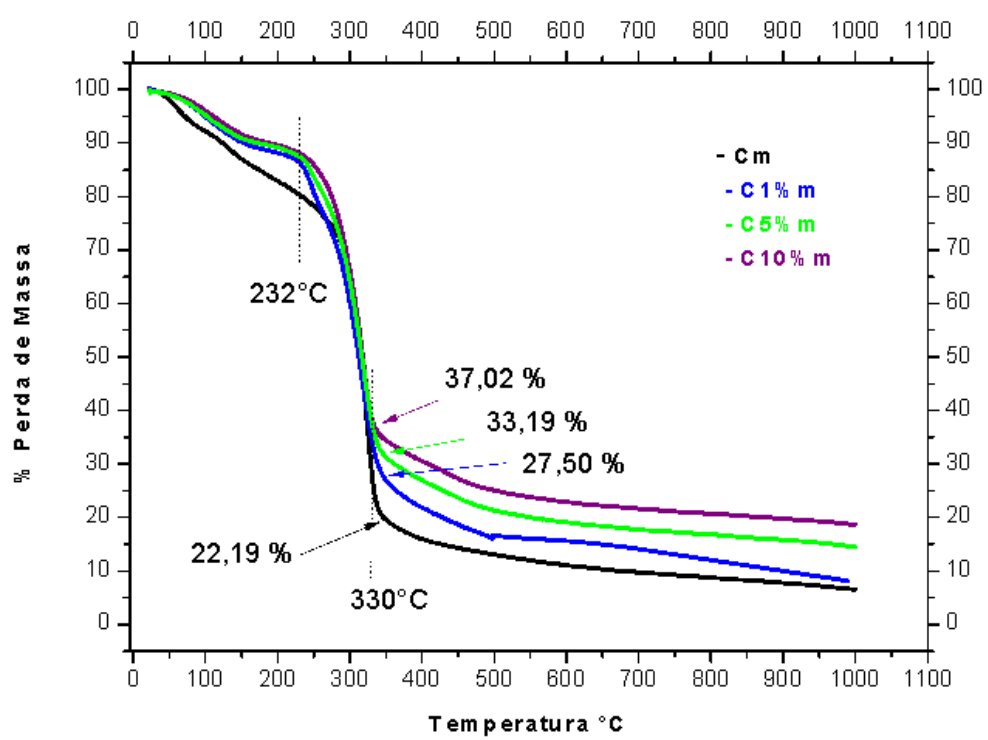

Figura 11: Análises termogravimétricas das amostras $\mathrm{C}, \mathrm{C} 1 \%, \mathrm{C} 5 \%$ e $\mathrm{C} 10 \%$.

Comparativamente, as amostras que não sofreram modificação química com metacrilato de glicidila iniciaram o processo de degradação a uma temperatura maior, excetuando a formulação $\mathrm{C} 10 \%$. Tal fato está relacionado quantidade de interações do tipo ligação de hidrogênio entre os polímeros, o que acarreta a necessidade de mais energia para romper estas interações desestabilizando a matriz favorecendo a degradação térmica. Sugere-se que o comportamento térmico na amostra C10\% deve-se ao fato da má dispersão do reforço na matriz. Conforme evidenciado na técnica de DRX não houve a intercalação da argila na matriz, essa dispersão falha permite que haja a diminuição das interações comentadas acima facilitando a degradação do material final. [5] Entretanto, para a amostra com 1\% de reforço onde há a esfoliação do material houve aumento da temperatura de degradação, a qual foi iniciada em aproximadamente $278^{\circ} \mathrm{C}$. 


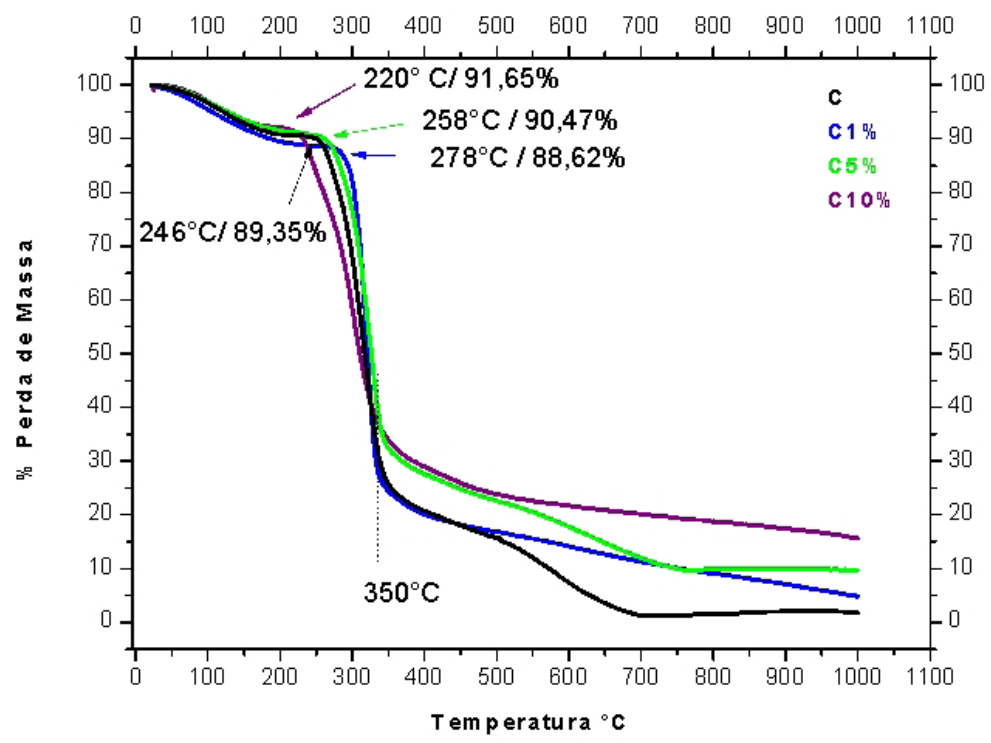

Figura 12: Análises termogravimétricas das amostras $\mathrm{Cm}, \mathrm{C} 1 \% \mathrm{~m}, \mathrm{C} 5 \% \mathrm{~m}$ e $\mathrm{C} 10 \% \mathrm{~m}$.

Os resultados das propriedades térmicas estão de acordo com o esperado após a substituição dos grupamentos -OH por vinílicos, assim como o aumento da estabilidade térmica com a adição da BNT está de acordo com os resultados encontrados na literatura. [16] A análise de todo o conjunto de resultados evidencia que a modificação química dos materiais gerou filmes compósitos extremamente promissores para embalagens alimentícias biodegradáveis.

\section{CONCLUSÕES}

A argila BNT, utilizada como um agente de reticulação inorgânico permitiu a obtenção de filmes compósitos de amido/ PVA estáveis quimicamente, especialmente após a inserção de grupamentos vinílicos oriundos do metacrilato de glicidila. Os polímeros e argila modificados com metacrilato glicidila apresentaram resitência a tração $25 \%$ maior, $16 \%$ menos permeáveis a água em média sendo estáveis frente a esta (não se dissolvem). Notam-se estes efeitos especialmente para as formulações de composito sintetizadas a com 1\% de argila, também modifica a qual apresentou exfoliação do reforço na matriz, excelente equílibrio entre o aumento na resistência a tração e a diminuição no alongamento, alta estabilidade a água e permeabilidade $64 \%$ menor que a mesma formulação sem reformço mineral e $25 \%$ menor que a mesma formulação oriunda de materias precursores sem modificação química alguma. Entretanto a estabilidade térmica dos filmes modificados diminui em aproximadamente $40^{\circ} \mathrm{C}$ devido a diminuição dos grupamentos $\mathrm{OH}$, os quais foram substituídos pela reação com o GMA. Os compósitos obtidos com as características exibidas neste trabalho abrem uma ótima perspectiva para embalagens verdes (eco-friendly) biodegradáveis, principalmente quando aplicados a indústria alimentícia como cobertura em alimentos a fim de aumentar a resistência mecânica, manutenção da umidade e permeabilidade a gases.

\section{AGRADECIMENTOS}

Ao programa de pós-graduação em ciência e tecnologia de materiais - POSMAT, COMCAP-UEM, e a CAPES pelo suporte financeiro.

\section{BIBLIOGRAFIA}

[1] GAO, Y., DAI, Y., ZHANG, H., et al. "Effects of organic modification of montmorillonite on the performance of starchbased nanocomposite films", Applied Clay Science, v. 99, n. 9, pp. 201-206, Set. 2014.

[2] WANG, W., ZHANG, H., JIA, R., et al. "High performance extrusion blown starch/polyvinyl alcohol nanocomposites films”, Food Hydrocolloids, v. 79, n.6, pp. 534-543, Jun. 2018.

[3] CHUNG, Y., ANSARI, S., ESTEVEZ, L., et al. "Preparation and properties of biodegradable starch-clay nanocomposites", Carbohydrate Polymers, v. 79, n.2, pp. 391-396, Jan. 2010.

[4] ALI, S. S, TANG, X., FAUBION, J., "Structure and physical properties of starch/poly vinyl alcohol/sodium montmorillonite nanocomposites films", Journal of Agricultural and Food Chemistry, v. 59, n.23, pp. 12384-12395, Dec. 2011. 
[5] LIU, D.,BIAN, Q., WANG, Y., et al. "Effect of oxidation degrees of grapheme oxide on the structure and properties of poly (vinyl alcohol) composite films" Composites Science and Technology, v. 129, n.6, pp. 146-152, Jun. 2016.

[6] JUNIOR, M. G, BOTARO, V. R., NOVACK, K. M., et al. "Starch/PVA-based nanocomposites reinforced with bamboo nanofibrils" Industrial Crops and Products, v. 70, n.8, pp. 72-83, Ago. 2015.

[7] CANO, A. I, CHÁFER, M., CHIRALT, A., et al. "Physical and microstructural properties of biodegradable films based on pea starch and PVA” Journal of Food Engineering, v. 167, n.12, pp. 59-64, Ago. 2015.

[8] MITTAL, A., GARG, S., KOHLI, D., et al. "Effect of cross linking of PVA/starch and reinforcement of modified barley husk on the properties of composite films", Carbohydrate Polymers, v. 151, n.10, pp. 926-938, Oct. 2016

[9] GARG, S., JANA, A. K., "Preparation of LDPE—acetylated/butyrylated starch blend blow films and characterization", Chinese Journal of Polymer Science, v.32, n.3, pp 268-279. Marc. 2014

[10] REIS, A. V., SCHUQUEL, I.T.A., GUILHERME, M.R., et al. "Reaction of Glycidyl Methacrylate at the Hydroxyl and Carboxylic Groups of Poly(vinyl alcohol) and Poly(acrylic acid): Is This Reaction Mechanism Still Unclear?", Journal Organic Chemistry, v. 74, n.10, pp 3750-3757. Mai. 2009.

[11] SHAFIK, S. S., MAJEED, K.J., KAMIL, M. I., "Preparation of PVA/corn starch blend films and studying the influence of gamma irradiation on mechanical properties", International Journal of Material Science and Applications, v. 3, n.2, pp25-28. Feb. 2014.

[12] ACKAR, D., BABIC, J., SUBARIC, D., et al. "Isolation of starch from two wheat varieties and their modification with epichlorohydrin”, Carbohydrate Polymers, v. 81, n.1, pp 76-82. May. 2010.

[13] GAO, F. G., LI, D., BI, C., MAO, Z., et al. "Preparation and characterization of starch crosslinked with sodium trimetaphosphate and hydrolyzed by enzymes", Carbohydrate Polymers, v. 103, n.15, pp 310-318. May. 2014.

[14] AHMAD, S., ASHRAF, S.M., RIAZ, U., et al. "Development of novel waterbone poly(1-naphthylamine)/poly (vinyalcohol)-resorcinol formaldehydecured corrosion resistant composite coatings", Progress in Organic Coatings, v. 62, n.1, pp 32-39. Marc. 2008.

[15] YOON, S., PARK, M., BYUN, H., "Mechanical and water barrier properties of starch/PVA composites films by adding nano-sized poly (methyl methacrylate-co-acrylamide) particles”, Carbohydrate Polymers, v. 87, n.1, pp 676-686. Jan. 2012.

[16] GUILHERME, M.R., FAJARDO, A.R., MOIA, T.A., et al. "Porous nanocomposite hydrogel of vinyled montmorillonite - crosslinked maltodextrin”, European Polymer Journal, v. 46, n.4, pp 1465-1474. Apr. 2010.

[17] CRISPIM, E.G., RUBIRA, A.F., MUNIZ, E.C., "Addition of methacryloil groups to poly(vinyl alcohol) in DMSO catalized by TEMED: Optimization through response surface methodology", Polymer Testingl, v. 25, n.3, pp 377-383. May. 2006.

[18] FROST, K., BARTHES, J., KAMINSKI, D., et al. "Thermoplastic starch-silica-polyvinyl alcohol composites by reactive extrusion”, Carbohydrate Polymers, v. 84, n.1, pp 343-350. Feb. 2011.

[19] CHENG, J., ZHENG, P.,ZHAO, F., et al. "The composites based on plasticized starch and carbon nanotubes", International Journal of Biological Macromolecules, v. 59, n.8, pp 13-19. Aug. 2013.

[20] USMAN, A., HUSSAIN, Z., RIAZ, A., et al. "Enhanced mechanical, thermal and antimicrobial properties of poly (vinyl alcohol)/grapheme oxide/starch/silver nanocomposites films", Carbohydrate Polymers, v. 153, n.20, pp 592-599. Nov. 2016.

[21] MONTEIRO, M.K.S., OLIVEIRA, V.R.L., SANTOS, F.K.G., et al. "Incorporation of bentonite clay in cassava starch films for the reduction water vapor permeability”, Food Research International, v. 105, n.3, pp 637-644. Mar. 2018.

[22] GLENN, G.M., BINGOL, G., CHIOU, B., et al. "Sodium bentonite-based coatings containing starch for protecting structures in wildfire emergency situations", Fire Safety Journal, v. 51, n.6, pp 85-92. Jul. 2012.

[23] ROMERO-BASTILDA, C.A., TAPIA-BLACIDO, D.R., MÉNDEZ-MONTEALVO, M., et al. "Effect of amylose content and nanoclay incorporation order in physicochemical properties of starch/montmorillonite composites", Carbohydrate Polymers, v. 152, n.5, pp 351-360. Nov. 2016.

[24] TIAN, H., WANG, K., LIU, D., YAN, J., XIANG, A., et al. "Enhanced mechanical and thermal properties of poly (vinyl alcohol)/ corn starch blends by nanoclay intercalation", International Journal of Biological Macromolecules, v. 101, n.3, pp 314-320. Mar. 2017. 
[25] LARA, S.C., SALCEDO, F., "Gelatinization and retrogradation phenomena in starch/montmorillonite nanocomposites plasticized with different glycerol/water ratios”, Carbohydrate Polymers, v. 151, n.20, pp 206-212. Mar. 2016.

[26] ASTM - American Society for Testing and Materials - E-96-00; Annual Book of ASTM Standards, ASTM: Philadelphia, 2002.

\section{ORCID}

Alberto Gonçalves Vieira de Carvalho Neto

Dayse Iara dos Santos

Sandra Regina Rissato

Margarida Juri Saeki

Silvia Luciana Favaro

Eduardo Radovanovic

Diogo Silva Pellosi https://orcid.org/0000-0003-3518-0913

https://orcid.org/0000-0002-9280-4334

https://orcid.org/0000-0002-1426-9356

https://orcid.org/0000-0002-0452-3701

https://orcid.org/0000-0002-3963-1892

https://orcid.org/0000-0001-7859-955X

https://orcid.org/0000-0002-6835-0600 